\title{
Interleukin 27 Could Be Useful in the Diagnosis of Tuberculous Pleural Effusions
}

\author{
Luis Valdés MD PhD, Esther San José MD, Lucía Ferreiro MD, Antonio Golpe MD PhD, \\ Francisco Gude MD PhD, José M Álvarez-Dobaño MD, Marco F Pereyra MD, \\ María E Toubes MD, and Francisco J González-Barcala MD PhD
}

\begin{abstract}
BACKGROUND: The diagnosis of tuberculous pleural effusion (TBPE) has some limitations. We studied the efficacy of interleukin-27 (IL-27) in the diagnosis of TBPE. METHODS: We measured IL-27, adenosine deaminase (ADA), ADA-2, interferon-gamma (IFN $\gamma$ ), and the ADA-IL-27 and ADA-2-IL-27 products in all the pleural effusion fluids. The diagnostic yield of IL-27 was evaluated with receiver operating characteristic curves. RESULTS: Of 431 pleural effusions, 70 were tuberculous, 146 were neoplastic, 58 were parapneumonic, 28 were empyemas, 88 were transudates, and 41 were other types. With a cutoff point of $0.55 \mathrm{ng} / \mathrm{mL}$, IL-27 had a sensitivity of $91.4 \%$ and a specificity of $85.1 \%$, which were significantly less than ADA, ADA-2, IFN $\gamma$, ADA-IL-27, or ADA2-IL-27. The area under the receiver operating characteristic curve for IL-27 $(0.963)$ was also significantly lower than that for the other markers, except for IFN $\gamma$. However, IL-27 improved the sensitivity of ADA and ADA-2 through ADA-IL-27 and ADA-2-IL-27 products (100\% for both). CONCLUSIONS: IL-27 is less efficient than ADA and ADA-2 in the diagnosis of TBPE. However, ADA-IL-27 and ADA-2-IL-27 improve the diagnostic sensitivity of ADA and ADA-2, and thus could be useful in situations of high clinical suspicion and low ADA level. A value above the cutoff point of the latter is practically diagnostic of TBPE. Key words: pleural disease; tuberculosis; interleukin. [Respir Care 2014;59(3):399-405. () 2014 Daedalus Enterprises]
\end{abstract}

\section{Introduction}

Tuberculosis is one of the most frequent causes of pleural effusion in Spain. ${ }^{1}$ Unfortunately, the conventional

\footnotetext{
Drs Valdés, Golpe, Álvarez-Dobaño, González-Barcala, Ferreiro, Pereyra, and Toubes are affiliated with Servicio de Neumología; Dr San José is affiliated with Servicio de Análisis Clínicos; and Dr Gude is affiliated with Unidad de Epidemiologia Clínica, Complejo Hospitalario ClínicoUniversitario de Santiago, Santiago de Compostela, Spain. Drs Valdés, Golpe, Álvarez-Dobaño, San José, Gude, and González-Barcala are also affiliated with Grupo Interdisciplinar de Investigación en Neumología, Instituto de Investigaciones Sanitarias de Santiago, de Compostela Santiago, Spain.
}

The authors have disclosed no conflicts of interest.

Correspondence: Luis Valdés MD PhD, Servicio de Neumología, Complejo Hospitalario Clínico-Universitario de Santiago, Travesia da Choupana s/n, 15706 Santiago de Compostela, Spain. E-mail: luis.valdes. cuadrado@sergas.es.

DOI: $10.4187 /$ respcare.02749 methods for diagnosing pleural inflammations have limitations, such as lack of yield by culture and staining, and wait-time to culture Mycobacterium tuberculosis. ${ }^{2,3}$

The analysis of pleural fluid interferon-gamma (IFN $\gamma$ ), adenosine deaminase (ADA), and its iso-enzymes, lysozyme, interleukin (IL), and lymphocyte subpopulations, ${ }^{4-9}$ has, in some cases, improved the diagnostic yield of tuberculous pleural effusion (TBPE). This way, with the determination of ADA (a reference when evaluating the usefulness of new biomarkers in the diagnosis of TBPE), it has been questioned whether, in view of the elevated ADA in young people who live in areas with a high tuberculosis incidence, a pleural biopsy needs to be performed to establish the diagnosis. ${ }^{10,11}$

Several studies have shown that IL-27, along with IL12 , plays an important role in regulating human macrophage function during infection and thus impeding $M$. tuberculosis growth. ${ }^{12,13} \mathrm{We}$ found no studies of the usefulness of IL-27 in the diagnosis of TBPE, and therefore studied the efficacy of IL-27 in the diagnosis of TBPE, 
comparing it with ADA, ADA-2, IFN $\gamma$, and the products ADA-IL-27 and ADA-2·IL-27.

\section{Methods}

This prospective study was approved by the Clinical Research Ethics Committee of Galicia (study 2012/216). All subjects signed the informed consent prior to any study procedures. We screened all patients admitted to the Chest Diseases Department of Complejo Hospitalario Universitario de Santiago, Santiago de Compostela, Spain, from January 2008 to April 2012. Pleural effusions were diagnosed as tuberculous if: caseous necrotic granulomas were found in pleural tissue; Ziehl-Neelsen stain or Lowenstein culture of pleural effusion fluid or pleural tissue were positive; or Ziehl-Neelsen stain or Lowenstein culture of sputum samples were positive if the pleural effusion was accompanied by pulmonary infiltration. The diagnoses of other pleural effusions were made per the criteria of Villena-Garrido et al. ${ }^{14}$

Pleural fluid samples were taken via thoracocentesis, at admission, before any treatment, and underwent ZiehlNeelsen staining, culture (in aerobic, anaerobic, and Lowenstein media), cytology, and biochemistry. Total cell counts were determined with a hematology system (Advia 2120, Siemens, Berlin, Germany). IL-27 was measured with an enzyme immunoassay (BioLegend, San Diego, California), per the manufacturer's protocol. ADA was measured with a coupled reaction with glutamate dehydrogenase and the rate of disappearance of nicotinamide adenine dinucleotide with high-energy hydrogen (NADH), measured at $340 \mathrm{~nm}$ in a spectrophotometer (Falcor 350, Menarini International, Florence, Italy). ${ }^{15}$ ADA-2 was measured via inhibition with erythro-9-(2-hydroxy-3-nonyl) adenine. ${ }^{16}$ IFN $\gamma$ was measured with an enzyme-linked immunosorbent assay kit (IFN $\gamma$ ELISA, IBL International, Hamburg, Germany, limit of detection 100 pg/mL, intraassay reproducibility $4.5 \%$, inter-assay reproducibility $5.7 \%$ ). Aliquots of the pleural fluid were centrifuged immediately, for $15 \mathrm{~min}$, at $1,500 \mathrm{~g}$, at $4^{\circ} \mathrm{C}$, and the supernatants were stored at $-80^{\circ} \mathrm{C}$. The closed pleural biopsies were performed with either a Cope or Abrams needle. ${ }^{17,18}$

\section{Statistical Analysis}

The Kolmogorov-Smirnov test was used to check the normality of data distribution, and non-normally distributed data were subjected to log transformations. The data are expressed as medians and 95\% CIs. The groups were compared with the Bonferroni post hoc multiple comparison test. Diagnostic performance was analyzed with receiver operating characteristic curves. ${ }^{19}$ The optimum cutoff point was considered the value that provided the greatest sum of sensitivity plus specificity. We calculated the op-

\section{QUICK LOOK}

\section{Current knowledge}

Tuberculosis is a frequent cause of pleural effusion. The diagnosis of tuberculous pleural effusion is complicated by low yield and the prolonged culture time for Mycobacterium tuberculosis.

\section{What this paper contributes to our knowledge}

Interleukin-27 (IL-27) was significantly higher in tuberculous pleural effusion than in other pleural effusions, but IL-27 was less sensitive and specific for diagnosis of tuberculous pleural effusion than were adenosine deaminase (ADA) and ADA-2. However, the products ADA-2-IL-27 and ADA-IL-27 had better sensitivity than ADA or ADA-2, respectively, for diagnosing tuberculous pleural effusion.

timum cutoff points, sensitivity, specificity, positive and negative likelihood ratios, and positive and negative predictive values with standard formulae. We used the method of DeLong et al to calculate the standard error of the area under the curve and the differences between areas under the curve. ${ }^{20}$ For the calculation of the receiver operating characteristic curves and areas under the curve we used statistics software (MedCalc 12.2.1.0, MedCalc, Marakerke, Belgium).

\section{Results}

We screened 519 patients admitted to our hospital during the study period. We excluded 88 for not having a definitive diagnosis. The remaining 431 were classified in 6 diagnostic groups: TBPE, neoplastic pleural effusions, parapneumonic pleural effusions (PPE), empyema pleural effusions, transudate pleural effusions, and miscellaneous other pleural effusions (Fig. 1 and Table 1).

The distributions of the biomarkers in each group of pleural effusions are summarized in Table 2. For all the biomarkers the median of the tuberculous group differed significantly from those of the other groups in all cases. The diagnostic thresholds obtained via receiver operating characteristic curve analysis were: IL-27 $0.55 \mathrm{ng} / \mathrm{mL}$, ADA $56 \mathrm{U} / \mathrm{L}$, ADA-2 $44.5 \mathrm{U} / \mathrm{L}$, IFN $\gamma 108.2 \mathrm{pg} / \mathrm{mL}$, ADA-IL-27 $7.6 \times 10^{3} \cdot \mathrm{U} \cdot \mathrm{ng} / \mathrm{L}^{2}$, and ADA-2.IL-27 $20.5 \times 10^{3} \cdot \mathrm{U} \cdot \mathrm{ng} / \mathrm{L}^{2}$. However, the receiver operating characteristic curves (Fig. 2) show that IL-27 separated TBPEs from the rest of the groups less well than did ADA, ADA-2, ADA-IL-27, or ADA-2-IL-27. The area under the IL-27 receiver operating characteristic curve (0.943) was significantly smaller than that of ADA (0.963), ADA-2 (0.991), 


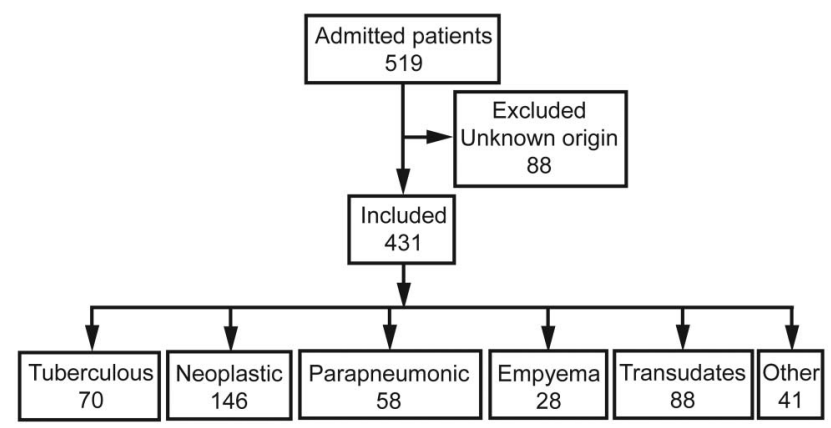

Fig. 1. Flow chart.

Table 1. Etiologies of Pleural Effusions in 431 Subjects in Spain

\begin{tabular}{|c|c|}
\hline Etiology & no. \\
\hline Tuberculous & 70 \\
\hline \multicolumn{2}{|l|}{ Neoplastic } \\
\hline Bronchogenic carcinoma & 72 \\
\hline Breast & 20 \\
\hline Lymphoma & 18 \\
\hline \multicolumn{2}{|l|}{ Stomach } \\
\hline \multicolumn{2}{|l|}{ Colon } \\
\hline \multicolumn{2}{|l|}{ Prostate } \\
\hline \multicolumn{2}{|l|}{ Melanoma } \\
\hline \multicolumn{2}{|l|}{ Thyroid } \\
\hline \multicolumn{2}{|l|}{ Uterus } \\
\hline \multicolumn{2}{|l|}{ Bladder } \\
\hline \multicolumn{2}{|l|}{ Pancreas } \\
\hline \multicolumn{2}{|l|}{ Phaeochromocytoma } \\
\hline \multicolumn{2}{|l|}{ Ovary } \\
\hline \multicolumn{2}{|l|}{ Esophagus } \\
\hline \multicolumn{2}{|l|}{ Thymus } \\
\hline \multicolumn{2}{|l|}{ Kidney } \\
\hline \multicolumn{2}{|l|}{ Mesothelioma } \\
\hline \multicolumn{2}{|l|}{ Uncertain } \\
\hline \multicolumn{2}{|l|}{ Parapneumonic } \\
\hline \multicolumn{2}{|l|}{ Empyema } \\
\hline \multicolumn{2}{|l|}{ Transudate } \\
\hline \multicolumn{2}{|l|}{ Heart failure } \\
\hline \multicolumn{2}{|l|}{ Hepatic hydrothorax } \\
\hline \multicolumn{2}{|l|}{ Hypoalbuminemia } \\
\hline \multicolumn{2}{|l|}{ Miscellaneous } \\
\hline \multicolumn{2}{|l|}{ Post-surgery } \\
\hline \multicolumn{2}{|l|}{ Hemothorax } \\
\hline \multicolumn{2}{|l|}{ Thoracic traumatism } \\
\hline \multicolumn{2}{|l|}{ Pulmonary thromboembolism } \\
\hline \multicolumn{2}{|l|}{ Hepatic abscess } \\
\hline \multicolumn{2}{|l|}{ Systemic lupus erythematosus } \\
\hline \multicolumn{2}{|l|}{ Subdiaphragmatic infection } \\
\hline Sudphrenic abscess & 1 \\
\hline Chylothorax & 1 \\
\hline
\end{tabular}

ADA·IL-27 (0.991), or ADA-2·IL-27 (0.994), but not significantly different than IFN $\gamma(0.953)$.
The IL-27, ADA, ADA-2 and IFN $\gamma$ levels were significantly higher in the TBPE group than in the other pleuraleffusion groups (Fig. 3). All the TBPEs had biomarker values above the cutoff points, except for 6 subjects for IL-27 (91.4\%), 1 subject for ADA (98.6\%), 3 subjects for ADA-2 (95.8\%), and 7 subjects for IFN $\gamma(90 \%)$. Subthreshold levels of IL-27, ADA, ADA-2, and IFN $\gamma$ were found in $85.1 \%, 93.6 \%, 97.5 \%$, and $90.6 \%$, respectively, in the non-tuberculous pleural effusions. The ADA-IL-27 and ADA-2-IL-27 values were also significantly higher in the TBPE group than in the rest of the groups. Both ADA-IL-27 and ADA-2.IL-27 correctly classified all the TBPEs, as well as $94.2 \%$ (ADA-IL-27) and $99.1 \%$ (ADA2.IL-27) of the non-tuberculous pleural effusions.

Table 3 lists the numbers of misclassifications by each biomarker and group. From worst to best, IL-27 misclassified $13.9 \%$ of the effusions, IFN $\gamma 9.5 \%$, ADA and ADA-IL-27 5.8\%, ADA-2 2.3\%, and ADA-2 IL-27 0.9\%. There were significant differences between ADA-2 and ADA-2.IL-27 and the rest, but not between themselves. The misclassification rate for IL-27 did not differ significantly from that of IFN $\gamma$, but was significantly greater than those of ADA, ADA-2, ADA-IL-27, and ADA-2-IL27.

Table 4 lists the diagnostic performance of the biomarker: IL-27 had a sensitivity of $91.4 \%$, a specificity of $85.1 \%$, a positive likelihood ratio of 6.11 , and an negative likelihood ratio of 0.10 . The sensitivity of IL-27 was significantly lower than the other biomarkers, except for IFN $\gamma$ (no significance). The sensitivity of both ADA·IL-27 and ADA-2-IL-27 was significantly higher than the rest, and there were no differences between them. The specificity of IL-27 was significantly lower than the other biomarkers, whereas the specificity of ADA-2-IL-27 and ADA-2 were significantly higher than that of the other biomarkers, and there were no differences between them. In the correlation study, statistical significance was observed only between IFN $\gamma$ and ADA $(r=0.435, P=.002)$ and ADA-2 ( $\mathrm{r}=0.322, P=0.26)$. IL-27 did not correlate with any of the biomarkers.

The pleural biopsy showed caseating granulomas in $76 \%$ of the TBPE (57/75) and the pleural fluid culture was positive in $25.3 \%$ of these. IFN $\gamma$ was the only biomarker that had a significant association $(\mathrm{r}=0.48, P=.02)$ with the pleural fluid culture (data not shown).

\section{Discussion}

IL-27 was significantly higher in TBPE than in the other pleural effusion groups, but IL-27 was less sensitive and specific than ADA or ADA-2. ADA-2-IL-27 and ADA-IL-27 improved the sensitivity over ADA and ADA-2, respectively, in the diagnosis of TBPE. 
Interleukin 27 Could Be Useful in the Diagnosis of Tuberculous Pleural Effusions

Table 2. Interleukin 27, Adenosine Deaminase, Interferon Gamma, and Adenosine Deaminase Products Levels in 431 Subjects With Pleural Effusion

\begin{tabular}{|c|c|c|c|c|c|c|c|}
\hline & \multicolumn{7}{|c|}{ Type of Pleural Effusion } \\
\hline & Tuberculous & Neoplastic & Parapneumonic & Empyema & Transudate & Miscellaneous & Unknown \\
\hline Subjects, $\mathrm{n}$ & 70 & 146 & 58 & 28 & 88 & 41 & 88 \\
\hline Male, \% & 47.1 & 59.6 & 67.2 & 67.9 & 60.2 & 51.2 & 61.5 \\
\hline $\begin{array}{l}\text { Age, } \\
\quad \text { mean } \pm \mathrm{SD} y\end{array}$ & $39.5 \pm 22.1$ & $67.3 \pm 13.4^{*}$ & $68.8 \pm 18.3^{*}$ & $62.4 \pm 16.1^{*}$ & $73.3 \pm 13.8^{*}$ & $63.7 \pm 13.3^{*}$ & $73.4 \pm 12.8$ \\
\hline IL-27, ng/mL & 1.18 (0.99-1.34) & $0.29 *(0.26-0.32)$ & $0.31 *(0.26-0.35)$ & $0.12 \dagger(0.01-0.18)$ & $0.33 *(0.26-0.39)$ & $0.33 *(0.26-0.37)$ & \\
\hline $\mathrm{ADA}, \mathrm{U} / \mathrm{L}$ & $117.5(98.5-125.5)$ & $23.3^{*}(821.5-25.4)$ & $25 *(22.0-27.0)$ & $45.5 *(27.7-157.1)$ & $12 *(10 .-13.1)$ & $23^{*}(17.9-28.9)$ & $24(22-26)$ \\
\hline ADA-2, U/L & $106.4(92.6-116.5)$ & $19.2 *(16.7-21.3)$ & $19 *(15.5-24.3)$ & $19.5 *(15.1-21.5)$ & $11 *(9.0-12.8)$ & $17.4 *(12.4-27.8)$ & $25.1(18-30.5)$ \\
\hline $\mathrm{IFN} \gamma, \mathrm{pg} / \mathrm{mL}$ & $1,021(611.8-2400)$ & $15.2 *(8.8-28.7)$ & $30.6^{*}(17.6-64.5)$ & $15.1 *(6.6-27.6)$ & $22.2 *(15.0-28.6)$ & $17.9 *(7.9-28.2)$ & $22.9(11.6-110.7)$ \\
\hline $\begin{array}{l}\text { ADA IL-27, } \\
10^{3} \cdot \mathrm{U} \cdot \mathrm{ng} / \mathrm{L}^{2}\end{array}$ & $117.6(106.5-135.8)$ & $5.9 *(5.0-7.0)$ & $7.1 *(5.7-9.1)$ & $5 *(2.1-8.0)$ & $3.3 *(2.9-4.2)$ & $6.3 *(4.7-9.4)$ & \\
\hline $\begin{array}{r}\text { ADA-2.IL-27, } \\
10^{3} \cdot \mathrm{U} \cdot \mathrm{ng} / \mathrm{L}^{2}\end{array}$ & $94.6(87.6-125.6)$ & $4.4 *(3.6-5.5)$ & $5.5^{*}(3.9-5.8)$ & $0.9 *(0.2-3.1)$ & $2.9 *(2.4-3.8)$ & $5.5 *(3.1-9.1)$ & \\
\hline $\begin{array}{l}\text { Values are median and } \\
\begin{aligned} * P<.001 . \\
\dagger P=.001 .\end{aligned} \\
\text { IL }=\text { interleukin } \\
\text { ADA }=\text { adenosine dea } \\
\text { IFN } \gamma=\text { interferon gam }\end{array}$ & $\begin{array}{l}\text { 95\% CI unless otherwise in } \\
\text { aminase } \\
\text { nma }\end{array}$ & ndicated. The values in the & e tuberculous group were & significantly different $f$ & $\mathrm{~m}$ the values in all 5 & groups. & \\
\hline
\end{tabular}
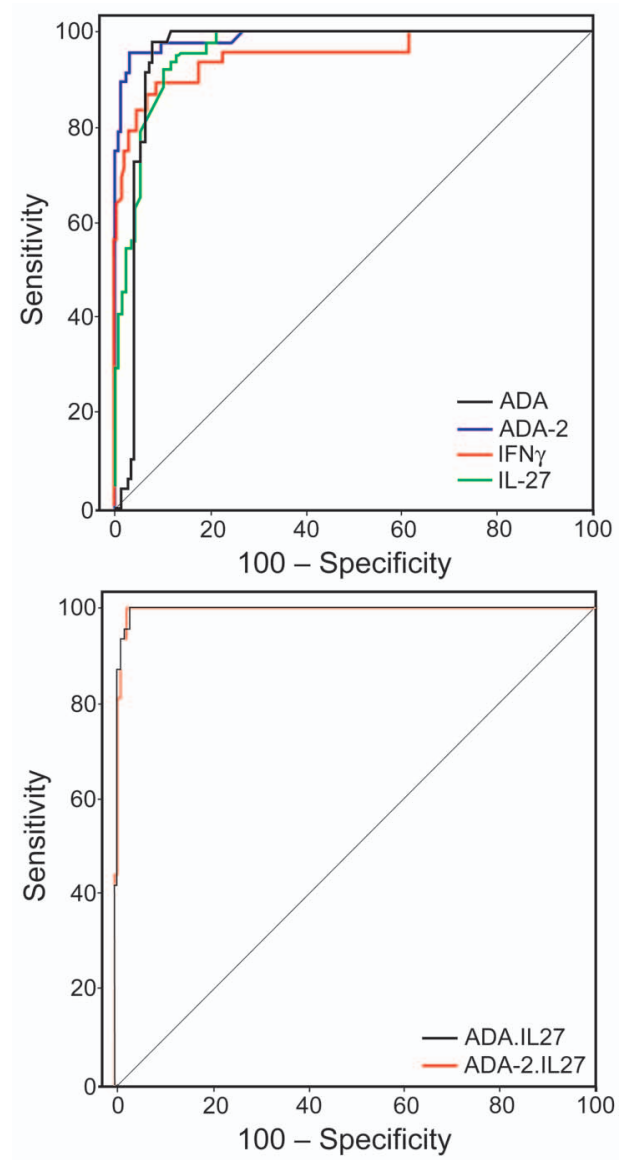

Fig. 2. Receiver operating characteristic curves for diagnosis of tuberculous pleural effusions with: (top) interleukin-27 (IL-27), adenosine deaminase (ADA), adenosine deaminase 2 (ADA-2), and interferon gamma (IFN $\gamma)$; (bottom) ADA.IL products.
Macrophages represent a bridge between the innate and adaptive immunity. In the early innate response, macrophages recognize microbes by their pattern recognition receptors such as toll-like receptors, leading to the transcription of IL-27 and other cytokines. Once secreted, the cytokines stimulate the adaptive immune response in lymphocytes. ${ }^{21} \mathrm{IL}-27$, a heterodimeric cytokine consisting of the Epstein-Barr-virus-induced gene 3 products and the p28 polypeptide, is produced earlier, by active antigen presenting cells in response to the microbial infection. It is capable of inducing $\mathrm{CD} 4+$ clonal proliferation in naive $\mathrm{CD} 4+\mathrm{T}$ cells, but not in memory cells. T cells synergize with IL- 12 in the production of IFN $\gamma$ by naive CD4 T cells. ${ }^{22}$

Our results indicate that the majority of TBPEs can be identified by high IL-27 (sensitivity 91.4\%), although its specificity is somewhat lower $(85.1 \%)$. That sensitivity and specificity are significantly lower than that of the other biomarkers, except for the sensitivity of IFN $\gamma$. All the non-tuberculosis pleural effusions had values higher than the established cutoff point (21 neoplastic, 10 parapneumonic, 3 empyema, 13 transudate, and 7 miscellaneous), always higher in number than any of the other biomarkers, except ADA in the empyema group.

Fourteen of the 21 misclassified neoplastic pleural effusions were lymphomas, which accounted for $77.8 \%$ of them (14/18) (median 1.05, 95\% CI 0.7-1.26). No significant differences were found in this subgroup as regards TBPE $(P=.26)$. This could explain the observation that splenocytes of mice with different types of cancer produce high concentrations of IFN $\gamma$ in blood, which could pro- 

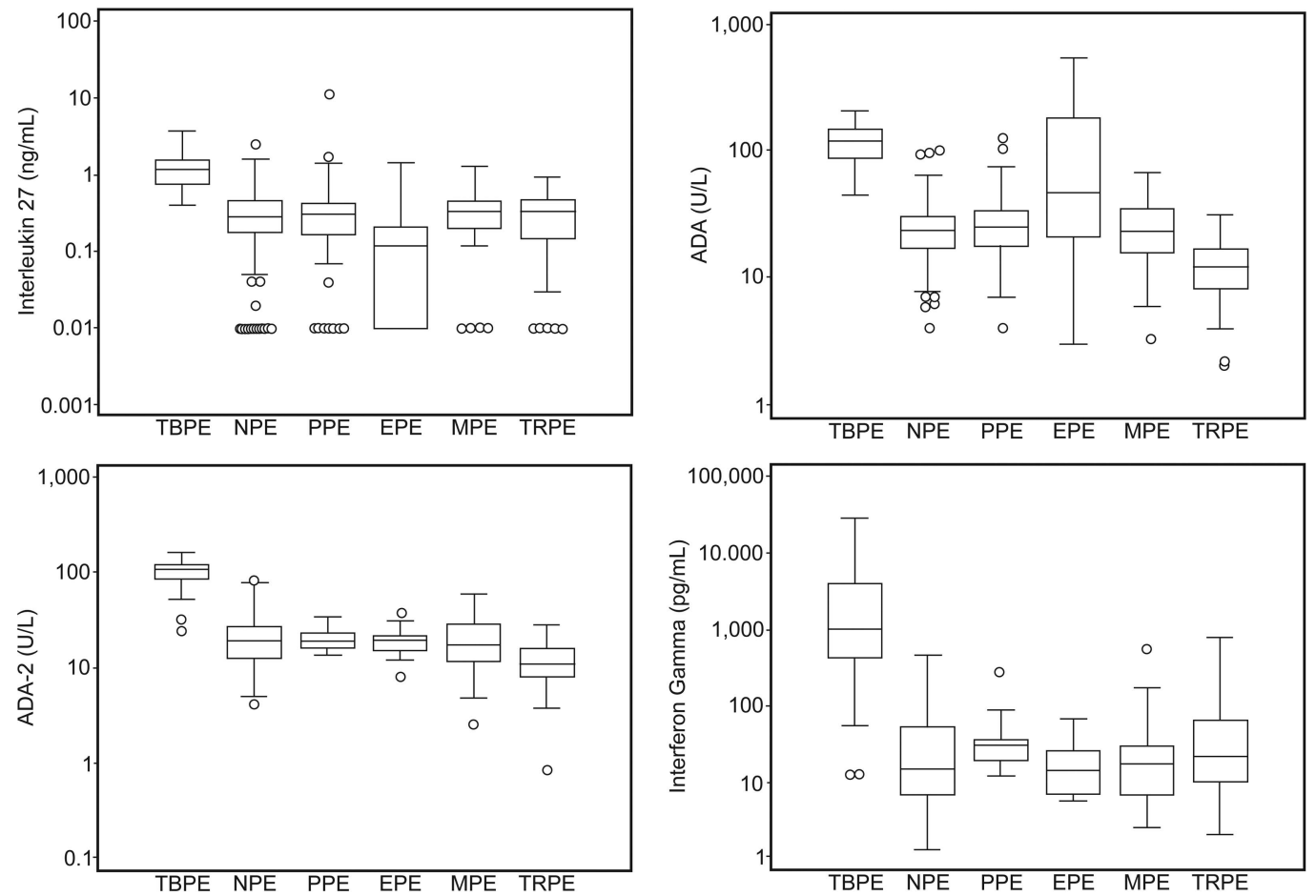

Fig. 3. Pleural fluid concentrations of interleukin 27, adenosine deaminase (ADA), adenosine deaminase-2 (ADA-2), and interferon gamma in 6 etiologies of pleural effusion: tuberculous (TBPE), neoplastic (NPE), parapneumonic (PPE), empyema (EPE), miscellaneous (MPE), and transudates (TRPE). Pleural ADA, ADA-2, IFN $\gamma$, and IL-27 are plotted on a log scale. In each data bar, the middle line represents the median, the bottom and top of the bar represent the 25th and 75th percentiles, the whiskers represent the minimum and maximum values excluding outliers, and the circles represent outliers.

Table 3. Numbers of Misclassified Pleural Effusions

\begin{tabular}{|c|c|c|c|c|c|c|}
\hline & \multicolumn{6}{|c|}{ Biomarker and Cutoff Value } \\
\hline & $\begin{array}{c}\mathrm{ADA} \\
>56 \mathrm{U} / \mathrm{L}\end{array}$ & $\begin{aligned} & \text { ADA-2 } \\
> & 44.5 \mathrm{U} / \mathrm{L}\end{aligned}$ & $\begin{array}{c}\text { IFN } \gamma \\
>108.2 \mathrm{pg} / \mathrm{mL}\end{array}$ & $\begin{array}{c}\mathrm{IL}-27 \\
>0.55 \mathrm{ng} / \mathrm{mL}\end{array}$ & $\begin{array}{c}\text { ADA } \cdot \mathrm{IL}-27 \\
>27.610^{3} \cdot \mathrm{U} \cdot \mathrm{ng} / \mathrm{L}^{2}\end{array}$ & $\begin{array}{c}\text { ADA-2·IL-27 } \\
>20.510^{3} \cdot \mathrm{U} \cdot \mathrm{ng} / \mathrm{L}^{2}\end{array}$ \\
\hline Tuberculous & $1(1.4)$ & $3(4.2)$ & $7(10)$ & $6(8.6)$ & $0(0)$ & $0(0)$ \\
\hline Neoplastic & $5(3.4)$ & $7(4.8)$ & $20(13.7)$ & $21(14.4)$ & $14(9.6)$ & $3(4.9)$ \\
\hline Parapneumonic & $5(8.6)$ & $0(0)$ & $6(10.3)$ & $10(17.2)$ & $6(10.3)$ & $0(0)$ \\
\hline Empyema & $13(46.4)$ & $0(0)$ & $0(0)$ & $3(10.7)$ & $2(7.1)$ & $0(0)$ \\
\hline Miscellaneous & $1(2.4)$ & $2(4.9)$ & $4(9.8)$ & $7(10.2)$ & $3(7.3)$ & $1(4.2)$ \\
\hline Transudate & $0(0)$ & $0(0)$ & $4(4.5)$ & $13(14.8)$ & $0(0)$ & $0(0)$ \\
\hline Total & $25(5.8 \%)$ & $12(2.3 \%)$ & $41(9.5 \%)$ & $60(13.9)$ & $25(5.8)$ & $4(0.9)$ \\
\hline $\begin{array}{l}P \text { for comparisons with total } \\
\text { misclassified with ADA-2 }\end{array}$ & .02 & & $<.001$ & $<.001$ & .02 & .17 \\
\hline $\begin{array}{l}P \text { for comparison with total } \\
\text { misclassified with IL-27 }\end{array}$ & .001 & $<.001$ & .057 & & .001 & $<.001$ \\
\hline $\begin{array}{l}\text { Values are number and percent. } \\
\mathrm{ADA}=\text { adenosine deaminase } \\
\mathrm{IFN} \gamma=\text { interferon gamma } \\
\mathrm{IL}=\text { interleukin }\end{array}$ & & & & & & \\
\hline
\end{tabular}

duce high levels of IL-27. ${ }^{23,24}$ In infectious diseases, IL-27 shows anti-inflammatory activity by suppressing the response of the T-helper-2 cells, ${ }^{25}$ which could explain the high IL-27 values in some parapneumonic and empyema pleural effusions. In any case, no previous studies have measured IL-27 in pleural fluid, so we need to study our 
Interleukin 27 Could Be Useful in the Diagnosis of Tuberculous Pleural Effusions

Table 4. Diagnosic Performance of Interleukin 27, Adenosine Deaminase, Interferon Gamma, and Adenosine Deaminase/Interleukin 27 Products for Tuberculous Pleural Effusion

\begin{tabular}{|c|c|c|c|c|c|c|c|}
\hline & Threshold & $\begin{array}{c}\text { Sensitivity } \\
\%\end{array}$ & $\begin{array}{c}\text { Specificity } \\
\%\end{array}$ & $\begin{array}{l}\text { Positive } \\
\text { Likelihood } \\
\text { Ratio }\end{array}$ & $\begin{array}{l}\text { Negative } \\
\text { Likelihood } \\
\text { Ratio }\end{array}$ & $\begin{array}{l}\text { Positive } \\
\text { Predictive } \\
\text { Value }\end{array}$ & $\begin{array}{c}\text { Negative } \\
\text { Predictive } \\
\text { Value }\end{array}$ \\
\hline IL-27 & $>0.55 \mathrm{ng} / \mathrm{mL}$ & 91.4 & 85.1 & 6.11 & 0.10 & 54.2 & 98.1 \\
\hline $\mathrm{ADA}$ & $>56 \mathrm{U} / \mathrm{L}$ & 98.6 & 93.4 & 14.9 & 0.01 & 74.2 & 99.7 \\
\hline ADA-2 & $>44.5 \mathrm{U} / \mathrm{L}$ & 95.7 & 97.5 & 38.3 & 0.04 & 88.2 & 99.2 \\
\hline $\mathrm{IFN} \gamma$ & $>108.2 \mathrm{pg} / \mathrm{mL}$ & 90 & 90.9 & 9.90 & 0.11 & 64.9 & 97.9 \\
\hline ADA·IL-27 & $>27.610^{3} \cdot \mathrm{U} \cdot \mathrm{ng} / \mathrm{L}^{2}$ & 100 & 93.4 & 15.04 & 0.00 & 73.7 & 100 \\
\hline ADA-2·IL-27 & $>20.510^{3} \cdot \mathrm{U} \cdot \mathrm{ng} / \mathrm{L}^{2}$ & 100 & 98.9 & 90.25 & 0.00 & 94.6 & 100 \\
\hline \multicolumn{8}{|c|}{$\begin{array}{l}\mathrm{ADA}=\text { adenosine deaminase } \\
\mathrm{IL}=\text { interleukin } \\
\mathrm{IFN} \gamma=\text { interferon gamma }\end{array}$} \\
\hline
\end{tabular}

hypothesis on why IL can be elevated in non-tuberculous pleural effusions.

The yield of the rest of the biomarkers was similar to previous studies. ${ }^{8,26-28}$ In the present study the overall misclassification rate of ADA-2 was significantly lower than that of ADA, although this could be explained by the increased number of empyema pleural effusions in our series.

We previously found that the increase in ADA and its ADA-2 isoenzyme in TBPE was a reflection of macrophage activation due to greater activation of CD4+ lymphocytes in pleural fluid. ${ }^{6}$ Several meta-analyses and subsequent studies ${ }^{29-32}$ have indicated that IFN $\gamma$ has a high yield in the diagnosis of TBPE (sensitivity 89\%, specificity 97\%). However, in the present study, as in others by our group, ${ }^{4,8}$ its yield has been lower, although within the range obtained in the meta-analyses (sensitivity 64-100\%, specificity $86-100 \%$ ). This could be due to disparities between the studies included in the meta-analyses, as regards the subjects (range 21-595), the observed prevalence of tuberculosis $(13.8-74.2 \%)$, or the methods of determination.

We have found that ADA-IL-27 and ADA-2-IL-27 improve the diagnostic yield over ADA and its isoenzyme ADA-2, respectively, in TBPE. The rationale for using ADA-IL-27 and ADA-2·IL-27, being both elevated in pleural effusion fluid, was that they could better differentiate TBPE from those who only have one of the biomarkers above the cutoff. Thus, we expected that the products of TBPE were higher than those of non-tuberculous pleural effusions. The yield of these products should be higher than that obtained from the requirement of values of ADA (or ADA-2) and IL-27 above the cutoff point, because this would lose sensitivity, although it would gain specificity. By contrast, requiring the achievement of only one of 2 values will increase sensitivity at the expense of decreasing specificity. There were significant differences in the sensitivity for both products (ADA 98.6\% vs ADA·IL-27
$100 \%, P=.004$, ADA-2 $95.7 \%$ vs ADA-2 IL-27 $100 \%$, $P=.001$ ), but not in the specificity (both ADA and ADA-IL-27 93.4\%, ADA-2 97.5\% vs ADA-2·IL-27 $98.9 \%)$. Only 4 subjects $(1.1 \%)$ with a non-tuberculous pleural effusions had elevated ADA-2·IL-27, with all the TBPEs well classified, so a value $>20.510^{3} \cdot \mathrm{U} \cdot \mathrm{ng} / \mathrm{L}^{2}$ of this biomarker in pleural fluid is practically diagnostic of TBPE (positive likelihood ratio 90.9).

As expected, there were significant relationships between ADA, ADA-2, and IFN $\gamma$. There was no significant relationship between IL-27 and IFN $\gamma(\mathrm{r}=-0.24)$. Human macrophages infected by $M$. tuberculosis, in response to IL-12, secrete IFN $\gamma$. Robinson et al observed increased IFN $\gamma$ production after neutralizing IL-27 with a soluble receptor (sIL-27R). ${ }^{13}$ This suggests that the activities of IL-27 and IL-12 could be antagonistic to the macrophages. However, both synergize in the production of IFN $\gamma$ in CD4+ and natural killer T cells. ${ }^{13}$ IL-27, unlike IL-12, induces T-helper-1 cell differentiation, even in the presence of anti-IFN $\gamma$ neutralizing antibodies, which suggests that IFN $\gamma$ is not necessary for this. On the other hand, once IL-12 has been produced in sufficient quantities (it is produced after IL-27), it appears that this may not be necessary for the maintenance of the T-helper- 1 cells. ${ }^{33,34}$ This could explain the lack of correlation that we found between IL-27 and IFN $\gamma$. In turn, the fact that increased IL-27 may not be necessary once the immune response is initiated could explain why its diagnostic yield may be less than the other biomarkers we studied. Further study is required to confirm this hypothesis associated with the IL-12, IL-27, and IFN $\gamma$ levels in pleural fluid.

\section{Conclusions}

The observed elevation of IL-27 in TBPE suggests that IL-27 plays a role in the immune response to $M$. tuberculosis infection, although IL-27 is less efficient in the diagnosis of TBPE than is ADA or ADA-2. However, the 
products ADA-IL-27 and ADA-2·IL-27 improve the sensitivity (but not the specificity) of ADA and ADA-2, respectively, so a value of the latter above the cutoff point is practically diagnostic of TBPE. Thus, ADA.IL-27 and ADA-2-IL-27 should be of use in situations of high clinical suspicion and low ADA. Further studies are needed to elucidate the role of IL-27 in this process.

\section{REFERENCES}

1. Valdes L, Alvarez D, Valle JM, Pose A, San Jose E. The etiology of pleural effusions in an area with high incidence of tuberculosis. Chest 1996;109(1):158-162.

2. Valdes L, Alvarez D, San Jose E, Penela P, Valle JM, García-Pazos JM, et al. Tuberculous pleurisy: a study of 254 patients. Arch Intern Med 1998;158(18):2017-2021.

3. Escudero Bueno C, Garcia Clemente M, Cuesta Castro B, Molinos Martín L, Rodríguez Ramos S, González Panizo A, Martínez GlezRío J. Cytologic and bacteriologic analysis of fluid and pleural biopsy specimens with Cope's needle: study of 414 patients. Arch Intern Med 1990;150(6):1190-1194.

4. Valdes L, San Jose E, Alvarez D, Sarandeses A, Pose A, Chomón B, et al. Diagnosis of tuberculous pleurisy using the biologic parameters adenosine deaminase, lysozyme, and interferon gamma. Chest 1993; 103(2):458-465.

5. Valdes L, Pose A, San Jose E, Martinez Vazquez JM. Tuberculous pleural effusions. Eur J Intern Med 2003;14(2):77-88.

6. Valdes L, San Jose E, Alvarez D, Valle JM. Adenosine deaminase (ADA) isoenzyme analysis in pleural effusions: diagnostic role, and relevance to the origin of increased ADA in tuberculous pleurisy. Eur Respir J 1996;9(4):747-751.

7. Fontan-Bueso J, Verea-Hernando H, Garcia-Buela JP, DominguezJuncal L, Martin-Egana MT, Montero-Martinez MC. Diagnostic value of simultaneous determination of pleural adenosine deaminase and pleural lysozyme/serum lysozyme ratio in pleural effusions. Chest 1988;93(2):303-307.

8. Valdes L, San Jose E, Alvarez Dobano JM, Golpe A, Valle JM, Penela P, González Barcala FJ. Diagnostic value of interleukin-12 p40 in tuberculous pleural effusions. Eur Respir J 2009;33(4):816820.

9. San Jose ME, Valdes L, Saavedra MJ, De Vega JM, Alvarez D, Viñuela J, et al. Lymphocyte populations in tuberculous pleural effusions. Ann Clin Biochem 1999;36(Pt 4):492-500.

10. Valdes L, Alvarez D, San Jose E, Juanatey JR, Pose A, Valle JM, et al. Value of adenosine deaminase in the diagnosis of tuberculous pleural effusions in young patients in a region of high prevalence of tuberculosis. Thorax 1995;50(6):600-603.

11. Valdes L, San Jose ME, Pose A, Gude F, González-Barcala FJ, Alvarez-Dobaño JM, Sahn SA. Diagnosing tuberculous pleural effusion using clinical data and pleural fluid analysis. A study of patients less than 40 years-old in an area with a high incidence of tuberculosis. Respir Med 2010;104(8):1211-1217.

12. Robinson CM, Nau GJ. Interleukin-12 and interleukin-27 regulate macrophage control of Mycobacterium tuberculosis. J Infect Dis 2008;198(3):359-366.

13. Robinson CM, O’Dee D, Hamilton T, Nau GL. Cytokines involved in interferon- $\gamma$ production by human macrophages. J Innate Immun 2010;2(1):56-65.

14. Villena-Garrido V, Ferrer Sancho J, Hernandez-Blasco L, de Pablo Gafas A, Pérez Rodríguez E, Rodríguez Panadero F, et al. Diagnosis and treatment of pleural effusion. Arch Bronconeumol 2006;42(7): 349-372.
15. Ellis G, Goldberg DM. A reduced nicotinamide adenine dinucleotide-linked kinetic assay for adenosine deaminase activity. J Lab Clin Med 1970;76(3):507-517.

16. Giusti G, Gakis C. Temperature conversion factors, activation energy, relative substrate specificity and optimum $\mathrm{pH}$ of adenosine deaminase form human serum and tissues. Enzyme 1971;12(4):417425.

17. Cope C. New pleural biopsy needle. JAMA 1958;167(9):1107-1108.

18. Abrams LD. New inventions: a pleural biopsy punch. Lancet 1958; 271(7010):30-31.

19. Zweig MH, Campbell G. Receiver-operating characteristic (ROC) plots: a fundamental evaluation tool in clinical medicine. Clin Chem 1993;39(4):561-577.

20. DeLong ER, DeLong DM, Clarke-Pearson DL. Comparing the areas under two or more correlated receiver operating characteristic curves: a nonparametric approach. Biometrics 1988;44(3):837-845.

21. Pirhonen J, Sirén J, Julkunen I, Matikainen S. IFN $\gamma$ regulates Tolllike receptor-mediated IL-27 gene expression in human macrophages. J Leukoc Biol 2007;82(5):1185-1192.

22. Pflanz S, Timans JC, Cheung J, Rosales R, Kanzler H, Gilbert J, et al. IL-27, a heterodimeric cytokine composed of EBI3 and p28 protein, induces proliferation of naive CD4+ T cells. Immunity 2002; 16(6):779-790.

23. Oniki S, Nagai H, Horikawa T, Furukawa J, Belladonna ML, Yoshimoto $\mathrm{T}$, et al. Interelukin-23 and interleukin-27 exert quite different antitumour and vaccine effects on poorly immunogenic melanoma. Cancer Res 2006;66(12):6395-6404.

24. Hisada M, Kamiya S, Fujita K, Belladonna ML, Aoki T, Koyanagi $\mathrm{Y}$ et al. Potent antitumour activity of interleukin-27. Cancer Res 2004;64(3):1152-1156.

25. Villarino AV, Huang E, Hunter CA. Understanding the pro- and anti-inflammatory properties of IL-27. J Immunol 2004;173(2):715720.

26. Gopi A, Madhavan SM, Sharma SK, Sahn SA. Diagnosis and treatment of tuberculous pleural effusion in 2006. Chest 2007;131(3): 880-889.

27. Porcel JM, Esquerda A, Bielsa S. Diagnostic performance of adenosine deaminase activity in pleural fluid: a single-center experience with over 2,100 consecutive patients. Eur J Intern Med 2010;21(5): 419-423.

28. Liang QL, Shi HZ, Wang K, Qin SM, Qin XJ. Diagnostic accuracy of adenosine deaminase in tuberculous pleurisy: a meta-analysis. Respir Med 2008;102(5):744-754.

29. Jiang J, Shi HZ, Liang QL, Qin SM, Qin XJ. Diagnostic value of interferon- $\gamma$ in tuberculous pleurisy. Chest 2007;131(4):1133-1141.

30. Greco S, Girardi E, Masdangelo R, Capoccetta GB, Saltini C. Adenosine deaminase and interferon gamma measurements for the diagnosis of tuberculous pleurisy: a meta-analysis. Int J Tuberc Lung Dis 2003;7(8):777-786.

31. Dheda K, Van Zyl-Smit RN, Sechi LA, Badri M, Meldau R, Meldau $\mathrm{S}$, et al. Utility of quntitative T-cell responses versus unstimulated interferón- $\gamma$ for the diagnosis of pleural tuberculosis. Eur Respir J 2009;34(5):1118-1126.

32. Dheda K, Van-Zyl Smit RN, Sechi LA, Badri M, Meldau R, Symons $\mathrm{G}$, et al. Clinical diagnostic utility of IP-10 and LAM antigen levels for the diagnostic of tuberculous pleural effusions in a high burden setting. PloS One 2009;4(3):e4689.

33. Hunter CA, Kastelein R. Interleukin-27: balancing protective and pathological immunity. Immunity 2012;37(6):960-969.

34. Owaki T, Asakawa M, Morishima N, Hata K, Fukai F, Matsui M, et al. A role for IL-27 in early regulation of Th1 differentiation. J Immunol 2005;175(4):2191-2200. 